\title{
Impending Labor
}

National Cancer Institute

\section{Source}

National Cancer Institute. Impending Labor. NCI Thesaurus. Code C92813.

The period of time prior to the beginning of childbirth labor; common signs and symptoms include nesting, anxiety, excitement, loss of mucous plug, increased urinary frequency and loose bowel movements. 